\title{
Full Activation of RNaseL in Animal Cells Requires Binding of 2-5A Within Ankyrin Repeats 6 to 9 of This Interferon-Inducible Enzyme
}

\author{
MARGARITA DÍAZ-GUERRA, ${ }^{1,2}$ CARMEN RIVAS, ${ }^{1}$ and MARIANO ESTEBAN ${ }^{1}$
}

\begin{abstract}
To define protein domains important for activation of the interferon (IFN)-induced enzyme 2-5A-dependent RNaseL, we have generated vaccinia virus $(\mathrm{VV})$ recombinants able to express in cultured cells truncated forms of this protein and compared their biologic activities with those producing the wild-type enzyme, with and without coexpression of 2-5A synthetase. Our results show that full activation of RNaseL requires binding of 2-5A oligonucleotides within amino acid positions 212-339, corresponding to ankyrin repeats 6 to 9. The protein kinase and ribonuclease domains of $R$ Nase $L$, amino acids 340-741, are sufficient for a constitutively active enzyme that is unresponsive to excess 2-5A. These results demonstrate in vivo the importance of the ankyrin domains in the biologic function of RNaseL. We suggest that ankyrin repeats act as key modulators of RNaseL activity.
\end{abstract}

\section{INTRODUCTION}

$\mathbf{E}$ NDORIBONUCLEASE L (RNASEL) is an interferon (IFN)-inducible enzyme (reviewed in refs. 1-3) present in mammalian cells as a component of the 2-5A system, an IFN-regulated RNA degradative pathway. ${ }^{(4)}$ Other proteins in this system are the double-stranded (ds)-RNA activated synthetases that produce $5^{\prime}$-triphosphorylated oligoadenylic acid (referred to as $2-5 \mathrm{~A})$ that binds to and activates RNaseL. ${ }^{(1)}$ During virus infection, dsRNA is frequently produced, and activation of the 2$5 \mathrm{~A}$ pathway is one of the mechanisms used by IFN to inhibit virus multiplication (reviewed in refs. 1, 5), directly demonstrated in the case of picornaviridae, ${ }^{(6-8)}$ vaccinia virus $(\mathrm{VV}),{ }^{(9)}$ and human immunodeficiency virus-1 (HIV-1). ${ }^{(10)}$ The biologic significance of the 2-5A system probably goes beyond its antiviral activities, and it has been suggested that enzymes in this pathway also have tumor-suppressor activities. ${ }^{(11)}$ In this regard, the recent findings that activation of RNaseL causes death of cells by apoptosis ${ }^{(12-14)}$ might be a mechanism mediating anticellular and antiviral actions of IFN.

Sequence analysis of human RNaseL gene ${ }^{(15)}$ has shown that this protein is composed of three functional domains. At the N terminus are nine ankyrin-like repeats, immediately followed by a complete protein kinase domain and next to it, in the $\mathrm{C}$ terminus, the residues where the endoribonuclease activity is located. ${ }^{(16,17)}$ A truncated form of RNaseL lacking 89 amino acids at the $\mathrm{C}$-terminus but still capable of 2-5 A binding behaves as a dominant negative mutant in stable cell lines. ${ }^{(17)}$ Ankyrin repeats are about 33 amino acids long and have been involved in mediating interactions in many different types of proteins (reviewed in refs. 18, 19). Interestingly, the catalytically active form of purified recombinant 2-5A-dependent RNaseL is a homodimer that forms only on binding to $2-5 \mathrm{~A} .{ }^{(20)}$ Recently, a novel bifunctional protein kinase/endoribonuclease (Ire1p) was found in mammalian cells, ${ }^{(21)}$ which, similarly to its homolog in Saccharomyces cerevisiae, ${ }^{(22)}$ is an essential proximal sensor of the unfolded protein response pathway (UPR). The C-termini of these proteins present significant sequence similarity to the endoribonuclease domain of human RNaseL. ${ }^{(21,22)}$

To learn about the structural-functionl relationship of ankyrin domains in RNaseL, in this investigation we have studied the biologic function of truncated forms in vivo by using an expression system based on VV recombinants able to produce in mammalian cells enzymes in the 2-5A pathway that are active. ${ }^{(9,13)}$ Our findings provide the first in vivo mapping of functional domains of RNaseL and strongly suggest that the ankyrin repeats constitute key modulators of RNaseL activity.

${ }^{1}$ Centro Nacional de Biotecnología, CSIC, Campus Universidad Autónoma, Madrid, Spain.

${ }_{2}^{2}$ Present address: Instituto de Investigaciones Biomédicas “Alberto Sols,” UAM-CSIC, C/ Arturo Duperier, Madrid, Spain. 


\section{MATERIALS AND METHODS}

\section{Plasmids}

Human RNaseL gene contained in ZC-5 plasmid ${ }^{(15)}$ was kindly provided by Robert H. Silverman (Cleveland Clinic Foundation, Cleveland, OH). We generated plasmid pRSETRL for expression of RNaseL in Escherichia coli as described. ${ }^{(9)}$ It contains the coding sequence for RNaseL, lacking only nucleotides coding for the 21 amino acids at the N-terminus, fused to a sequence for 38 new amino acids that includes a stretch of 6 histidine residues and the first 12 amino acids of the bacteriophage T7 gene 10 leader peptide. We generated plasmid pRSET-N by Nco I digestion of pRSET-RL and religation. This plasmid is similar to pRSET-RL but lacks sequences coding for amino acids 228-741 of RNaseL. Plasmid pRSET-1S and pRSET-2S were generated by SacI digestion of pRSET-R1 and religation. The former encodes a protein differing from the product of pRSET-R1 in a deletion of amino acids 212-339 in RNaseL sequence. In pRSET-2S, the deletion is of amino acids $22-339$. Plasmid $\mathrm{pTM}-\Delta \mathrm{N}$ was obtained by cloning an NdeI + NcoI DNA fragment from pRSET-N into the SmaI site of VV insertion vector pTM 1-E. ${ }^{(23)}$ Similarly, we obtained plasmids pTM-RL, pTM- $\Delta 1 \mathrm{~S}$, and pTM- $\Delta 2 \mathrm{~S}$ by subcloning an NdeI DNA fragment from corresponding constructs in pRSET$\mathrm{B}$ into the same insertion vector. These plasmids contain sequences coding for 8 extra amino acids in the $\mathrm{N}$ terminus in front of the initiation codon provided by pRSET-B. Plasmid pSC-2-5AS was obtained as described ${ }^{(9)}$ and contains the $E$. coli $\beta$-galactosidase gene (lac z) under the control of a late viral promoter (p11) and human $40 \mathrm{kDa} 2-5 \mathrm{~A}$ synthetase gene under the control of an early and late viral promoter (p7.5).

\section{Cells and viruses}

African green monkey kidney cell line BSC-40 was grown in Dulbecco's modified Eagle's medium (DMEM) supplemented with $10 \%$ newborn calf serum. Cells were cultivated at $37{ }^{\circ} \mathrm{C}$ with $5 \% \mathrm{CO}_{2}$. The recombinant viruses VV-RL, VV- $\Delta \mathrm{N}$, and VV-2-5AS were obtained as described by introduction of

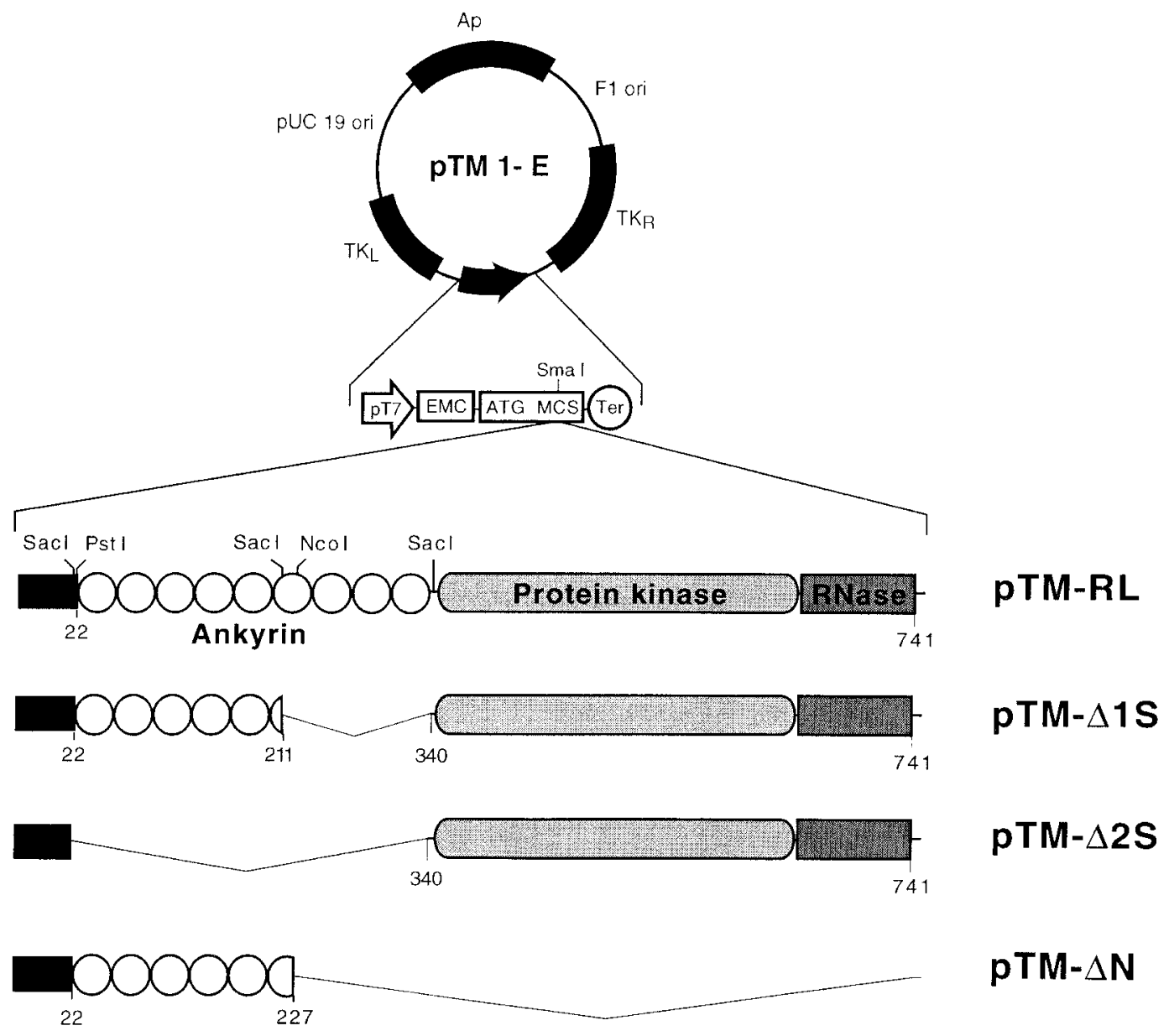

FIG. 1. Diagram of plasmid vectors for the expression of truncated forms of RNaseL by VV recombinants. The structures of the insertion plasmids pTM-RL, pTM- $\Delta 1 \mathrm{~S}$, pTM- $\Delta 2 \mathrm{~S}$, and pTM- $\Delta \mathrm{N}$ used to generate VV recombinants are shown. pT7, bacteriophage T7 polymerase promoter; EMC, encephalomyocarditis virus sequences for cap-independent translation; MCS, multiple cloning site; solid boxes, pRSET-B sequences comprising an ATG, 6 histidine residues, and the gene 10 leader peptide; open circles, ankyrin-like repeats in 2-5A-dependent RNaseL; gray oval, protein kinase homology region; gray rectangle, region required for RNase activity; Ter, T7 transcriptional terminator. Numbers correspond to amino acid positions in human RNaseL sequence. Other relevant regions in pTM1-E insertion vector are also shown. 
the insertion plasmids pTM-RL, pTM-N, and pSC-2-5AS, respectively, into the thymidine kinase $(t k)$ region of wild-type VV (WR) by homologous recombination. ${ }^{(9)}$ Using a similar procedure, we obtained recombinant viruses VV- $\Delta 1 \mathrm{~S}$ and VV- $\Delta 2 \mathrm{~S}$. Basically, plasmids pTM-1S and pTM-2S were transfected into BSC-40 cells using lipofectamine reagent (GIBCO BRL, Paisley, UK) as indicated by suppliers, and recombinant viruses were selected in human TK-143B cells using $5^{\prime}$-bromo-deoxyuridine $(25$ $\mu \mathrm{g} / \mathrm{ml}){ }^{(24)}$ Three rounds of plaque purification in this cell line yielded homogeneous virus preparations containing the desired genes, as confirmed by Southern blot DNA hybridization analysis. Expression of proteins RNaseL, RNaseL- $\Delta 1 \mathrm{~S}$, RNaseL- $\Delta 2 \mathrm{~S}$, and RNaseL- $\Delta \mathrm{N}$, produced by viruses VV-RL, VV- $\Delta 1 \mathrm{~S}$, VV$\Delta 2 \mathrm{~S}$, and VV-N, respectively, is under the control of a $\mathrm{T} 7$ promoter. The recombinant proteins contain at the N-terminus 46 additional amino acids, including a stretch of 6 histidine residues and the 12 amino acids gene 10 leader peptide ${ }^{(9)}$ Other TK viruses vTF7-3 (herein vT7) ${ }^{(25,26)}$ and VV-LUC, ${ }^{(27)}$ were as described.

\section{Analysis of low-molecular weight DNA}

Low-molecular weight DNA was isolated ${ }^{(28)}$ from cultured cells infected with the different VV recombinants under conditions described in Figure 4. The DNA was analyzed by $1.6 \%$ agarose gel electrophoresis, and it was visualized by staining with ethidium bromide. ${ }^{(13)}$

\section{Total RNA isolation}

Total cellular RNA from infected cells was isolated using the Ultraspec-II RNA Resin Purification System (Biotecx). For analysis, denatured RNA was fractionated on $1 \%$ formaldehyde-agarose gels and stained using ethidium bromide. ${ }^{(13)}$

\section{Analysis of protein synthesis}

For immunoblot analysis, protein samples were fractionated by SDS-polyacrylamide gel electrophoresis (SDS-PAGE) and transferred to nitrocellulose paper in a semidry blotting apparatus for $45 \mathrm{~min}$ at $200 \mathrm{~mA}$ and analyzed by immunoperoxidase staining after reactivity with different sera. Rabbit polyclonal serum specific for RNaseL was prepared as described. ${ }^{(9)}$ Monoclonal anti-T7 tag antibody (Novagen, Madison, WI) recognizing the gene 10 leader peptide in the N-terminus of fusion proteins was used at a 1:3000 dilution. Rabbit polyclonal serum was specific for 2-5A synthetase was kindly provided by Robert H. Silverman (Cleveland Clinic Foundation). Analysis of de novo protein synthesis was performed by labeling for the specified times with $\left[{ }^{35} \mathrm{~S}\right]$-labeled methionine + cysteine $(100$ $\mu \mathrm{Ci} / \mathrm{ml})$ in methionine and cysteine-free medium. After washing with phosphate-buffered saline (PBS), cells were immediately collected in lysis buffer, extracts were fractionated in SDSPAGE, and dried gels were autoradiographed

\section{RESULTS}

\section{Generation of $V V$ recombinants expressing truncated forms of RNaseL}

To investigate the structural-functional relationship of the ankyrin domains, we generated recombinants expressing trun- cated forms of RNaseL and analyzed them compared with fulllength enzyme (diagram of vectors in Fig. 1). Viruses VV- $\Delta 1 \mathrm{~S}$ and VV- $\Delta 2 \mathrm{~S}$ were obtained by homologous recombination of insertion vectors pTM- $\Delta 1 \mathrm{~S}$ and $\mathrm{pTM}-\Delta 2 \mathrm{~S}$, containing, respectively, RNaseL coding sequence lacking amino acids 212-339 or 1-339 into VV tk gene. ${ }^{(24)}$ Recombinant viruses VV-RL, producing nearly full-length RNaseL, and VV- $\Delta \mathrm{N}$, expressing a truncated RNaseL lacking amino acids 228-741, were described previously.(9) After three cycles of virus purification, the recombinant viruses were confirmed by Southern blot DNA hybridization (data not shown). To define protein expression, monkey kidney BSC-40 cells were infected with 2 pfu/cell of each recombinant $\mathrm{VV}$ and at $24 \mathrm{~h}$ after infection, cells were labeled with $\left[{ }^{35} \mathrm{~S}\right]$-methionine-cysteine for $2 \mathrm{~h}$, and the protein pattern was analyzed by SDS-PAGE and autoradiography. As shown in Figure 2A, all recombinant viruses induced proteins of expected size for wild-type RNaseL and truncated forms, RNaseL- $\Delta 1 \mathrm{~S}\left(\mathrm{M}_{\mathrm{r}} 68 \mathrm{kDa}\right)$, RNaseL- $\Delta 2 \mathrm{~S}\left(\mathrm{M}_{\mathrm{r}} 45 \mathrm{kDa}\right)$, and RNaseL- $\Delta N\left(M_{r} 25 \mathrm{kDa}\right)$. Because RNaseL genes were under the control of bacteriophage T7 promoters, proteins corresponding to different fragments were only obtained by coinfection of monkey kidney BSC-40 cells with a second recombinant virus (vTF7-3, herein vT7) that contains a T7 polymerase

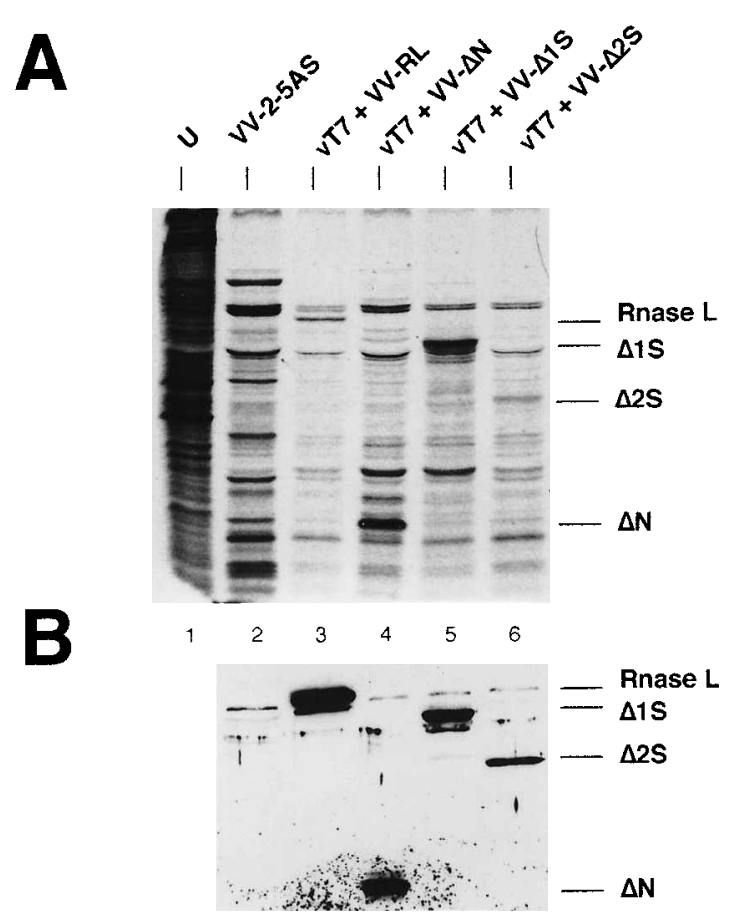

FIG. 2. Expression by VV recombinants of truncated forms of RNaseL in cultured cells. Monolayers of BSC-40 cells were infected with VV-2-5AS (moi 4 pfu/cell, lane 2) or doubly infected with vT7 + VV-RL (lane 3), vT7 + VV- $\Delta \mathrm{N}$ (lane 4), vT7 + VV- $\Delta 1 \mathrm{~S}$ (lane 5), or vT7 + VV- $\Delta 2 \mathrm{~S}$ (lane 6) (moi 2 $\mathrm{pfu} / \mathrm{cell}$ of each virus) for $24 \mathrm{~h}$. Cells were labeled with [ $\left.{ }^{35} \mathrm{~S}\right]-$ methionine-cysteine for $2 \mathrm{~h}$, and equal amounts of cell extracts $(30 \mu \mathrm{g})$ were fractionated in SDS- $10 \%$ polyacrylamide gels and analyzed by autoradiography(A) or by immunoblot, after transfer of proteins to nitrocellulose paper and reactivity with a rabbit polyclonal serum against RNaseL (B). Lane 1, uninfected cells. 
gene under the control of VV constitutive promoter $\mathrm{p} 7.5 .^{(25)} \mathrm{As}$ previously described, ${ }^{(9)}$ expression of wild-type RNaseL induces severe inhibition of viral and cellular protein synthesis (Fig. 2A, lane 3). Significantly, protein synthesis was differentially inhibited in cells infected with the mutant forms of RNaseL compared with wild-type enzyme or with cells infected with VV-2-5AS. The upper band in lane 2 (Fig. 2A) corresponds to $\beta$-galactosidase, whose gene is not present in the other VV recombinants under control of the T7 promoter. The identity of the recombinant proteins was confirmed by immunoblot analysis using rabbit polyclonal anti-RNaseL serum (Fig. 2B). The band intensities are different probably because of differences in binding of the antiserum, as the levels of protein expression were the lowest in cells infected with VV-RL.

\section{The ankyrin region of $R$ Nase $L$ is required for full endoribonuclease and translation inhibition activities, and the sequences responsible map to ankyrin repeats 6 to 9}

We have shown previously that at late times of infection, VV-RL causes the characteristic pattern of rRNA degradation that is indicative of RNaseL activation, as well as inhibition of virus protein synthesis ${ }^{(9)}$ and cell death by apoptosis. ${ }^{(13)} \mathrm{Com}$ bined expression of RNaseL with human $40 \mathrm{kDa} 2-5 \mathrm{~A}$ synthetase, produced by recombinant virus VV-2-5AS, further enhances the effects produced by RNaseL. ${ }^{(13)}$ To establish the importance of the ankyrin repeats in the biologic activity of RNaseL, monolayers of BSC-40 cells were infected with one VV recombinant expressing a truncated form of RNaseL in combination with vT7 or VV-2-5AS or both, using 2 pfu/cell of each virus. A total multiplicity of $6 \mathrm{pfu} / \mathrm{cell}$ was maintained all along the experiment by using an auxiliary recombinant virus VV-LUC, ${ }^{(27)}$ which is, as other recombinants used in this work, a $t k(-)$ virus. We extracted total cellular RNA $48 \mathrm{~h}$ after infection in order to perform rRNA degradation assays (Fig. 3A). In an attempt to quantify the endonuclease activity of the different forms of RNaseL, we have taken the amount of $28 \mathrm{~S}$ rRNA found in cells infected with vT7 + VV- $\Delta \mathrm{N}$ (Fig. 3A, lane 4) as $100 \%$, considering that cleavage is not observed in this situation. Because 2-5A accumulates at late times during VV infection, ${ }^{(29,30)}$ recombinant RNaseL becomes active in vT7 + VV-RL-infected cells, and severe cleavage is observed (Fig. $3 \mathrm{~A}$, lane 2 ), resulting in only $5.9 \%$ of the amount of $28 \mathrm{~S} \mathrm{rRNA}$ recovered in control cells. Interestingly, proteins RNaseL- $\Delta 1 \mathrm{~S}$ (Fig. 3A, lane 6) and RNaseL- $\Delta 2 \mathrm{~S}$ (Fig. 3A, lane 8) are also active and produce a characteristic pattern of rRNA fragments. The amount of $28 \mathrm{~S}$ rRNA found was, respectively, $35.3 \%$ and $21.2 \%$ of values obtained in cells expressing RNaseL- $\Delta N$. From this experiment, we conclude that truncated forms of RNaseL lacking up to 339 amino acids at the N-terminal region, which correspond to deletions of the ankyrin domain, still have endonuclease activity.

Coexpression of recombinant 2-5A synthetase further enhances RNaseL ribonuclease activity (Fig. 3A, compare lanes 2 and 3 ), and the amount of $28 \mathrm{~S}$ rRNA recovered is further reduced to $2.3 \%$ of control values. At $48 \mathrm{hr}$ after infection, cleavage of rRNA also could be observed in cells infected singly with VV-2-5AS (Fig. 3A, lane 1), probably because of low levels of activation of endogenous RNaseL, and only $13.5 \%$ of
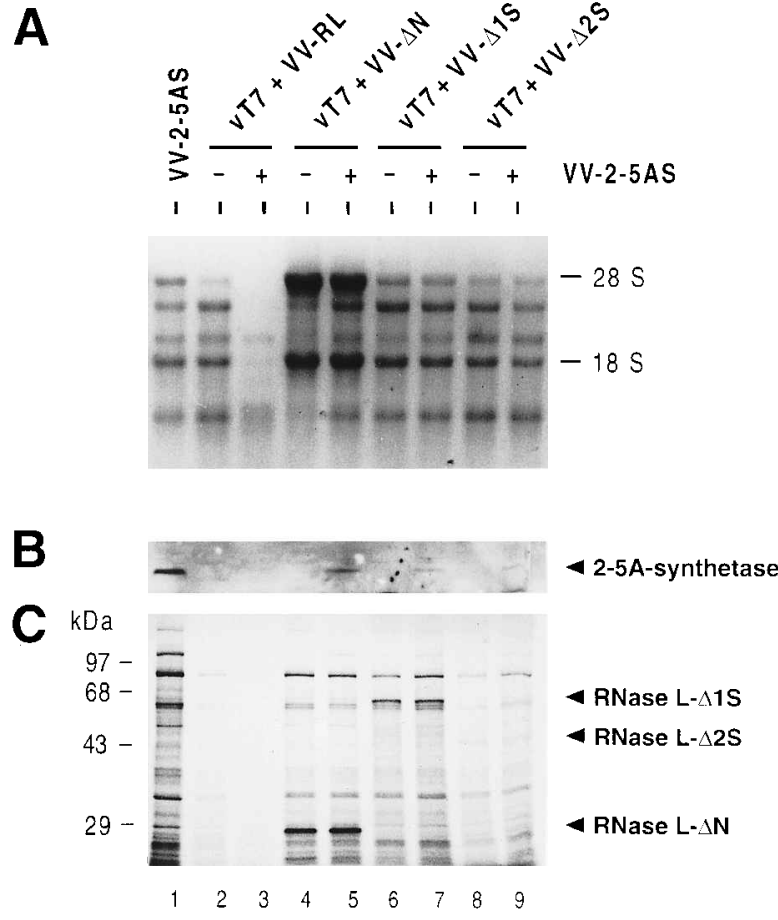

FIG. 3. Endoribonuclease activity and inhibition of protein synthesis on coexpression of truncated forms of RNaseL with 2-5A synthetase. Monolayers of BSC-40 cells were infected with the indicated combinations of viruses vT7, VV-RL, VV$\Delta 1 \mathrm{~S}, \mathrm{VV}-\Delta 2 \mathrm{~S}, \mathrm{VV}-\Delta \mathrm{N}$, and VV-2-5AS (moi $2 \mathrm{pfu} / \mathrm{cell}$ of each virus). Total multiplicity was maintained at $6 \mathrm{pfu} / \mathrm{cell}$ at all times using VV-LUC when required. (A) Analysis of RNA degradation. Total RNA was purified using the Ultraspec-II RNA Resin Purification System (Biotecx), and the amount of RNA corresponding to $3 \times 10^{5}$ cells was fractionated in $1 \%$ agarose-formaldehyde gels and stained with ethidium bromide. Abundant RNA, 28S and $18 \mathrm{~S}$ rRNA, are indicated. (B) Expression of $2-5 \mathrm{~A}$ synthetase. Cell extracts $(50 \mu \mathrm{g})$ were fractionated in SDS-10\% polyacrylamide gels, transferred to nitrocellulose, and immunoblotted using rabbit polyclonal sera specific for 2-5A synthetase. (C) De novo protein synthesis. Monolayers were infected for $24 \mathrm{~h}$ as before and labeled with $\left[{ }^{35} \mathrm{~S}\right]$ methionine+cysteine $(100 \mu \mathrm{Ci} / \mathrm{ml})$ for $15 \mathrm{~min}$ as described. Protein extracts $(50 \mu \mathrm{g})$ were fractionated, and dried gels were autoradiographed The lane numbers at the bottom refer to $\mathbf{A}, \mathbf{B}$, and $\mathbf{C}$.

$28 \mathrm{~S}$ rRNA was recovered. Synthesis of RNaseL- $\Delta 1 \mathrm{~S}, \Delta 2 \mathrm{~S}$, or $\Delta \mathrm{N}$ together with 2-5A synthetase modulates somehow the 2$5 \mathrm{~A}$ pathway, as there is a decrease in cleavage of rRNA relative to cells producing only $2-5 \mathrm{~A}$ synthetase (Fig. $3 \mathrm{~A}$, compare lanes 1 with lanes 5,7 , and 9). It is noteworthy that coexpression of 2-5A synthetase with RNaseL- $\Delta 1 \mathrm{~S}$ (Fig. 3A, lane 7) or RNaseL- $\Delta 2 S$ (Fig. 3A, lane 9) does not significantly enhance the level of RNA fragmentation produced (Fig. 3A, lanes 6 and 8 , respectively) as occurs for the full-length enzyme. The amount of 28S rRNA recovered in cells infected with vT7 + VV$\Delta 1 \mathrm{~S}+\mathrm{VV}-2-5 \mathrm{AS}$ or $\mathrm{vT} 7+\mathrm{VV}-\Delta 2 \mathrm{~S}+\mathrm{VV}-2-5 \mathrm{AS}$ was $25.9 \%$ and $14.7 \%$ of control values, compared with $35.3 \%$ and $21.2 \%$ obtained, respectively, if $2-5 \mathrm{~A}$ synthetase is not produced. Immunoblot analysis with a rabbit polyclonal sera specific for 2- 
5A synthetase (Fig. 3B) demonstrated synthesis of this enzyme in cells infected with VV-2-5AS, although the levels differed depending on the specific effect on protein synthesis of the form of RNaseL coexpressed.

A consequence of fragmentation of rRNA by activation of the 2-5A pathway is inhibition of protein synthesis. Thus, we analyzed de novo synthesis of proteins $24 \mathrm{~h}$ after infection (Fig. $3 \mathrm{C}$ ), a time when production of virus proteins is still active, whereas cellular protein synthesis is blocked. ${ }^{(31)}$ Monolayers of BSC-40 cells infected as before were pulse-labeled with $\left[{ }^{35} \mathrm{~S}\right]-$ methionine-cysteine $(100 \mu \mathrm{Ci} / \mathrm{ml})$ for $15 \mathrm{~min}$ in methionine and cysteine-free medium, and protein extracts were fractionated in SDS-polyacrylamide gels. Very low level of protein synthesis activity was obtained in cells expressing RNaseL (Fig. 3C, lane 2 ), which was further reduced by coexpression of 2-5A synthetase (Fig. 3C, compare lanes 2 and 3). However, expression of 2-5A synthetase had no direct effect on protein synthesis by itself at this time of infection, as already described (Fig. 3C, lane 1). Cells infected with $v \mathrm{~T} 7+\mathrm{VV}-\Delta \mathrm{N}$ presented protein levels that were similar in the absence or presence of 2-5A synthetase (Fig. 3C, lanes 4 and 5). The difference in protein synthesis observed for VV-2-5AS (lane 1) and vT7 + VV- $\Delta \mathrm{N}$ (lane 4) infected cells is probably due to increased expression of genes driven by polymerase $\mathrm{T} 7$ over $\mathrm{VV}$ promoters, as this effect was not observed in cells infected with VV-LUC (not shown). Interestingly, in cells infected with recombinant viruses VV- $\Delta 1 \mathrm{~S}$ (Fig. 3C, lane 6) and VV- $\Delta 2 \mathrm{~S}$ (Fig. 3C, lane 8) there was inhibition of protein synthesis that could not be enhanced by increased production of 2-5A (Fig. 3C, lanes 7 and 9). From the results shown in Figure 3, we conclude that the ankyrin region in RNaseL is required for full endonuclease activity, and the sequences responsible for activation by 2-5A map to ankyrin repeats 6 to 9 of RNaseL.

\section{Ankyrin domains 6 to 9 of RNase L are required for full induction of apoptosis by the 2-5A system}

Next, we analyzed the influence of ankyrin domains in the induction of apoptosis by the mutant forms of RNaseL. Thus, BSC-40 cells were infected as before, low molecular weight DNA was isolated at $48 \mathrm{~h}$ after infection, and DNA laddering was analyzed by $1.6 \%$ agarose gel electrophoresis containing $0.1 \mu \mathrm{g} / \mathrm{ml}$ ethidium bromide in Tris-acetate/EDTA buffer. As shown in Figure 4, cells infected with vT7+VV-RL presented internucleosomal DNA fragmentation indicative of apoptosis (Fig. 4, lane 3) that could not be observed in mock-infected cells (Fig. 4, lane 1) or in cells infected with VV-2-5AS (Fig. 4 , lane 2). DNA laddering was markedly increased by coexpressing 2-5A synthetase and RNaseL (Fig. 4, lane 4). Fragmentation of DNA was hardly detected in cells infected with vT7+VV- $\Delta \mathrm{N}$ (Fig. 4, lane 5), independently of coexpressing 2-5A synthetase (Fig. 4, lane 6). Interestingly, when 2-5A was not produced in excess (in the absence of VV-2-5AS), the levels of internucleosomal DNA fragmentation were similar between cells infected with vT7 +VV- $\Delta 2 \mathrm{~S}$ or vT7+VV-RL (Fig. 4, compare lanes 3 and 9) and lower in cells infected with vT7+ VV- $\Delta 1 \mathrm{~S}$ (Fig. 4, compare lanes 3 and 8). However, overproduction of $2-5 \mathrm{~A}$ by coinfections of truncated forms of RNaseL and VV-2-5AS did not enhance DNA ladder formation (Fig. 4, compare lanes 7 and 8, and 9 and 10, respec-

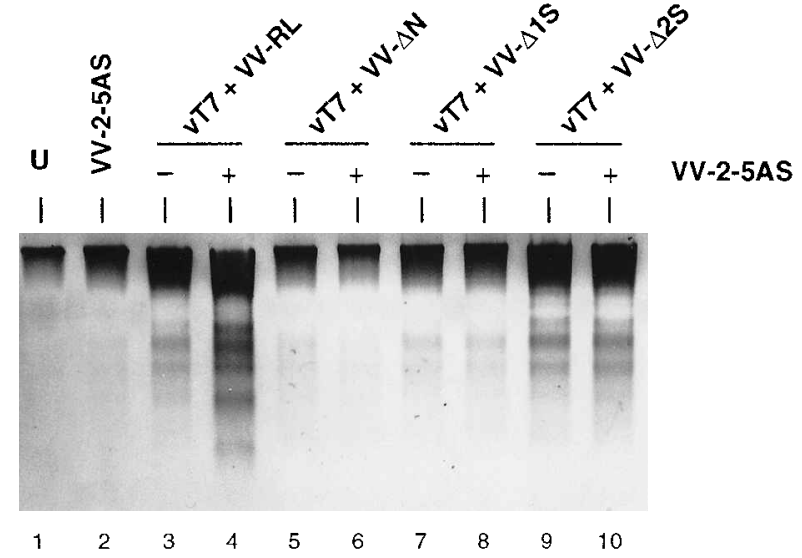

FIG. 4. Induction of apoptosis by coexpression of truncated forms of RNaseL with 2-5A synthetase. Monolayers of BSC40 cells were either mock-infected (lane 1) or infected with the indicated combinations of VV recombinant viruses (lanes 2-10) for $48 \mathrm{~h}$, as described in Figure 3. Low-molecular weight DNA $\left(3 \times 10^{6}\right.$ cell equivalents per lane $)$ was electrophoresed in an agarose gel and stained with ethidium bromide.

tively). These findings provide evidence that the ankyrin repeats 6 to 9 are required for full induction of apoptosis by the 2-5A system.

\section{DISCUSSION}

In this investigation, we have taken advantage of recombinants of VV able to express as active forms the IFN-inducible enzymes, RNaseL and 2-A synthetase. With the aim of identifying domains of RNaseL important for its biological function, we produced recombinant VV expressing truncated forms of RNaseL and compared their properties with those of viruses producing the full-length enzyme. Because deletion of a protein region may alter its stability or conformation or both and indirectly affect the activity of this protein, some caution must be exerted when analyzing results obtained with deletion mutants. However, our conclusions using intact mammalian cells basically confirm and extend results previously obtained using in vitro expression systems. ${ }^{(15,32)}$ In our in vivo assays, binding of 2-5A drives activation of RNaseL as an endoribonuclease, which causes inhibition of protein synthesis, the probable cause of inhibition of virus replication and of host cell death by apoptosis. As index of biologic activity of the 2-5A system, we evaluated endoribonuclease activity, inhibition of protein synthesis, and induction of apoptosis. Although inducible by IFN, basal levels of 2-5A synthetase are found in most, if not all, mammalian cells (reviewed in Ref. 2), which are responsible for the accumulation late during VV infection of high levels of 2-5A. ${ }^{(29,30)}$ This oligonucleotide is able to partially activate exogenously produced recombinant RNaseL in vT7+VV-RL-infected cells. ${ }^{(9)}$ However, the enzyme can be further activated if higher levels of 2-5A are produced by coexpression of recombinant 2-5A synthetase. As observed in this investigation, truncated forms of RNaseL have lower enzymatic activity than full-length enzyme in the presence of excess 2- 
$5 \mathrm{~A}$, proving that binding of the oligonucleotide is a requirement for full activation of RNaseL in vivo. Moreover, the ankyrin domain and, more precisely, amino acids 212-339 corresponding to part of repeat 6 and repeats 7 to 9 are critical for $2-5 \mathrm{~A}$ regulation. Interestingly, this same region was mapped before as the binding site of 2-5A by using an in vitro assay performed with murine RNaseL-deleted protein. ${ }^{(15)}$ Our data support recent findings by Dong and Silverman ${ }^{(32)}$ obtained with mutant RNaseL expressed in E. coli. These authors demonstrated that deletion of all nine ankyrin repeats in RNaseL produced a protein with unregulated ribonuclease activity similar to our results with RNaseL- $\Delta 2 \mathrm{~S}$. They have suggested that in the absence of $2-5 \mathrm{~A}$, the ankyrin domain might be interacting with the catalytic domain, blocking ribonuclease activity and preventing dimerization by impeding access to the sites involved in this interaction. Only after $2-5 \mathrm{~A}$ is bound is there a conformational change that allows dimer formation rendering an active ribonuclease. Our results extend the in vitro findings of Dong and Silverman ${ }^{(32)}$ and demonstrate in vivo that in the absence of all ankyrin repeats, the $\mathrm{C}$ terminal part of RNaseL is still biologically active, although to a lesser extent than wild-type RNaseL, suggesting constitutive activation of the enzyme. Full activation requires the presence of ankyrin repeats 6 to 9 , as revealed with the mutant form of RNaseL- $\Delta 1 \mathrm{~S}$. That RNaseL- $\Delta 1 \mathrm{~S}$ has enzymatic activity, although lower than that of RNaseL- $\Delta 2 \mathrm{~S}$, suggests that the modulatory domain is not fully comprised in ankyrin repeats 6 to 9 . It is not known if dimerization is required for ribonuclease activity or is just a mechanism to maintain an active conformation of RNaseL.

Our findings are also important to define the functionality of ankyrin repeats. The fact that these sequences have been found in functionally very diverse proteins from nearly all phyla as well as in animal viruses ${ }^{(19)}$ suggests that they do not serve a highly specialized function. Current evidence supports the idea that this motif is involved in interactions between distinct proteins and within regions of a single protein and, in some cases, in DNA binding. ${ }^{33,34)}$ Our results demonstrate that by interacting with small oligonucleotides, ankyrin repeats are key modulators of the biologic activity of proteins.

The presence of the protein kinase domain in RNaseL strongly suggests an additional level of regulation of the $2-5 \mathrm{~A}$ pathway throughout phosphorylation of different molecules of RNaseL or other proteins that might be interacting with RNaseL by the ankyrin repeats. Our expression system offers the opportunity to test these hypotheses.

\section{ACKNOWLEDGMENTS}

This investigation was supported by grants from Comision Interministerial de Ciencia y Tecnologia (CICYT) PM95-0022 and SAF95-0072 of Spain. The authors are very grateful to R. Silverman (Cleveland Clinic Foundation) for the generous gift of sera specific for 2-5A synthetase. We thank Claudia Gonzalez for performing the experiment with the results shown in Figure 2 and Victoria Jimenez for expert technical assistance. During the time of this investigation, C.R. was a recipient of a contract from X.G. of Spain.

\section{REFERENCES}

1. SAMUEL, C.E. (1991). Antiviral actions of interferon. Interferonregulated cellular proteins and their surprisingly selective antiviral activities. Virology 183, 1-11.

2. SEN, G.C., and LENGYEL, P. (1992). The interferon system. A bird's eye view of its biochemistry. J. Biol. Chem. 267, 5017-5020.

3. STAEHELI, P. (1990). Interferon-induced proteins and the antiviral state. Adv. Virus Res. 38, 147-200.

4. KERR, I.M., and BROWN, R.E. (1978). pppA2'p5'A2'p5'A: an inhibitor of protein synthesis synthesized with an enzyme fraction from interferon-treated cells. Proc. Natl. Acad. Sci. USA 75, 256-260.

5. JOKLIK, W.K. (1990). In: Virology, B.N. Fields, D.M. Knipe, et al. (eds.) New York: Raven Press, pp. 383-410.

6. CHEBATH, P.J., WHITE, R.F., ANTONIW, J.F., WALESBY, N.J., and KERR, I.M. (1987). Constitutive expression of $\left(2^{\prime}-5^{\prime}\right)$ oligo A synthetase confers resistance to picornavirus infection. Nature 330, 587-588

7. COCCIA, E.M., ROMEO, G., NISSIN, A., MARZIALLI, G., ALBERTINI, R., AFFABRIS, A., BATTISTINI, A., FIORUCCI, G., ORSSATI, R., ROSSI, G.B., and CHEBATH, J. (1990). A fulllength murine 2-5A synthetase cDNA transfected in NIH-3T3 cells impairs EMCV but not VSV replication. Virology 179, 228-233.

8. LI, X.-L., BLACKFORD, J.A., and HAPPEL, B. (1998). RNaseL mediates the antiviral effect of interferon through a selective reduction of viral RNA during encephalomyocarditis virus infection. J. Virol. 72, 2752-2759.

9. DÍAZ-GUERRA, M., RIVAS, C., and ESTEBAN, M. (1997). Inducible expression of the 2-5A-synthetase/RNaseL system results in inhibition of vaccinia virus replication. Virology 227, 220-228.

10. MATRA, R.K., and SIRVERMAN, R.H. (1998). Regulation of human immunodeficiency virus replication by $2^{\prime}, 5^{\prime}$-oligoadenylate dependent RNaseL. J. Virol. 72, 1146-1152.

11. LENGYEL, P. (1993). Tumor-suppressor genes: news about the interferon connection. Proc. Natl. Acad. Sci. USA 90, 5893-5895.

12. CASTELLI, J.A.C., HASSEL, B.A., WOOD, K.A., LI, X.-L., AMEMIYA, K., DALAKAS, M.C., TORRENCE, P., and YOULE, R.J. (1997). A study of the interferon antiviral mechanism: apoptosis activation by the 2-5A system. J. Exp. Med. 186, 967-972.

13. DIAZ-GUERRA, M., RIVAS, C., and ESTEBAN, M. (1997). Activation of the IFN-inducible enzyme RNaseL causes apoptosis of animal cells. Virology 236, 354-363.

14. ZHOU, A., PARANJAPE, J., BROWN, T.L., NIE, H., NAIK, S., DONG, B., CHANG, A., TRAPP, B., FAIRCHILD, R., COLMENARES, C., and SILVERMAN, R.H. (1997). Interferon action and apoptosis are defective in mice devoid of $2^{\prime}, 5^{\prime}$-oligoadenylatedependent RNaseL. EMBO J 16, 6355-6363.

15. ZHOU, A., HASSEL, B.A., and SILVERMAN, R.H. (1993). Expression cloning of 2-5A-dependent RNase: a uniquely regulated mediator of interferon action. Cell 72, 753-765.

16. BORK, P., and SANDER, C. (1993). A hybrid protein kinaseRNase in an interferon-induced pathway? FEBS Lett. 334, 149-152.

17. HASSEL, B.A., ZHOU, A., SOTOMAYOR, C., MARAN, A., and SILVERMAN, R.H. (1993). A dominant negative mutant of 2-5Adependent RNase suppresses antiproliferative and antiviral effects of interferon. EMBO J. 12, 3297-3304

18. BENNETT, V. (1992). Ankyrins. J. Biol. Chem. 267, 8703-8706.

19. BORK, P. (1993). Hundreds of ankyrin-like repeats in functionally diverse proteins: mobile modules that cross phyla horizontally. Proteins $\mathbf{1 7}, 363-374$.

20. DONG, B., and SILVERMAN, R.H. (1995). 2-5A-Dependent RNase molecules dimerize during activation by $2-5 \mathrm{~A}$. J. Biol. Chem. 270, 4133-4137.

21. TIRASOPHON, W., WELIHINDA, A.A., and KAUFMAN, R.J. 
(1998). A stress response pathway from the endoplasmic reticulum to the nucleus requires a novel bifunctional protein kinase/endoribonuclease (Irelp) in mammalian cells. Genes Dev. 12, 1812-1824.

22. SIDRAUSKI, C., and WALTER, P. (1997). The transmembrane kinase Irelp is a site-specific endonuclease that initiates mRNA splicing in the unfolded protein response. Cell 90, 1031-1039.

23. SUAREZ, P., DÍAZ-GUERRA, M., PRIETO, C., ESTEBAN, M., CASTRO, J.M., NIETO, A., and ORTIN, J. (1996). Open reading frame 5 of porcine reproductive and respiratory syndrome virus as a cause of virus-induced apoptosis. J. Virol. 70, 2876-2882.

24. AUSUBEL, F.M., BRENT, R., KINGSTON, R.E., MOORE, D.D., SEIDMAN, J.G., SMITH, J.A., and STRUHL, K. (Eds.) (1987) Current Protocols in Molecular Biology. New York: John Wiley \& Sons.

25. FUERST, T.R., NILES, E.G., STUDIER, F.W., and MOSS, B. (1986). Eukaryotic transient-expression system based on recombinant vaccinia virus that synthesizes T7 RNA polymerase. Proc. Natl. Acad. Sci. USA 83, 8122-8126.

26. MOSS, B., ELROY-STEIN, O., MIZUKAMI, T., ALEXANDER, W.A., and FUERST, T.R. (1990). New mammalian expression vectors. Nature 348, 91-92.

27. RODRIGUEZ, J.F., RODRIGUEZ, D., RODRIGUEZ, J.-R., McGOWAN, E.B., and ESTEBAN, M. (1988). Expression of the firefly luciferase gene in vaccinia virus: a highly sensitive gene marker to follow virus dissemination in tissues of infected animals. Proc. Natl. Acad. Sci. USA 85, 1667-1671.

28. HIRT, B. (1967). Selective extraction of polyoma DNA from infected mouse cell cultures. J. Mol. Biol. 27, 365-369.

29. ESTEBAN, M., and PAEZ, E. (1985). The 2-5A system and vaccinia virus. In: The 2-5A System: Molecular and Clinical Aspects of the Interferon Regulated 2-5A Pathway. B.R.G. Williams and R.H. Silverman (eds.) New York: Alan R. Liss, 202, 25-34.
30. RICE, A.P., ROBERTS, W.K., and KERR, I.M. (1984). 2-5A accumulates to high levels in interferon-treated vaccinia virus infected cells in the absence of any inhibition of virus replication. J. Virol. 50, 220-228.

31. LEE, S.B., and ESTEBAN, M. (1993). The interferon-induced double stranded RNA-activated protein kinase inhibits the replication of vaccinia virus. Virology 193, 1037-1041.

32. DONG, B., and SILVERMAN, R.H. (1997). A bipartite model of 2-5A-dependent RNaseL. J. Biol. Chem. 272, 22236-22242.

33. SIDOROVA, J., and BREEDEN, L. (1993). Analysis of the SWI4/SWI6 protein complex, which directs $\mathrm{G}_{1} / \mathrm{S}$-specific transcription in Saccharomyces cerevisiae. Mol. Cell. Biol. 13, 1069-1077.

34. THOMPSON, C.C., BROWN, T.A., and McKNIGHT, S.L. (1991). Convergence of Ets- and Notch-related structural motifs in a heteromeric DNA binding complex. Science 253, 762-768.

Address reprint requests to: Dr. Mariano Esteban Centro Nacional de Biotechnología

CSIC

Campus Universidad Autónoma

Madrid-28049

Spain

Tel: $34-91-585-4503$

Fax: 34-91-585-4506

E-mail: mesteban@cnb.uam.es

Received 24 June 1998/Accepted 12 October 1998 